\title{
Green Sharing: The Proposed Criteria in Green Building Standards to Promote the Usage of Natural Handicrafts in Building Materials
}

\author{
Aracha Krasae-In \\ Kasetsart University, Thailand
}

\begin{abstract}
Sustainable development has been a great challenge to the building and construction industry for decades. There have been many initiatives and attempts to create sustainability for the industry through the concept of the Green Building certificate in order to reduce the impact to environment and society while promoting better living conditions of the people involved in the project. This paper aims to examine all three aspects of sustainability; economy, environment and society, in the building and construction industry by proposing new criteria for the green building certificate. This will create opportunities for the community based handicraft building products to be specified and purchased to be used in the modern building and construction industry and share the economic value to the community.
\end{abstract}

\section{Introduction}

It is already known that the building and construction industry is one of the major causes of pollution and an impact to the environment. According to the EPA, the industry has created approximately one third of annual greenhouse gases and also consumed a large amount of material as well as produced an enormous amount of waste along its life time. This includes the extraction of construction materials, the transportation and production of material, the construction process and the operation of the building.

However, the scope of the green building sustainability was limited to the direct benefit of the construction and building. According to the research by McGraw-Hill [1], the most important reasons for the green building project in terms of social factors were "to promote greater health and well-being" and "to encourage sustainable business practices" while the most important in terms of environmental reasons were "to lower energy consumption" and "reduce greenhouse gas emissions".

The practice of sustainability was far beyond the minimalizing of impact but also to promote the betterment of society and environment. On the other hand, the businesses should share their profits to promote genuine sustainability.

\section{Sustainability and green building}

Sustainability is currently one of the world's most focal issues. Pressure from environmental concern from the changing of global climate, natural pollution and scarcer resources, the concept of sustainability is not only about good will, but a necessity for everyone.
According to the United Nation's World Commission on Environment and Development or the Brundtland's report [2], the word "sustainability" was defined as the goal for sustainable development which is identified as "The Three Pillars of Sustainability" including economic development, social development and environmental protection.

As mentioned earlier, the building and construction industry, which has been largely responsible for the impact to society and environment, had adopted the idea of sustainability. Initiatives were implemented in many countries in order to reduce the impact from design and construction which have developed into the green building standard and rating system all over the world.

Efforts towards sustainable building have been accompanied by the development of methods, tools, and systems to assess the sustainable performance of buildings. Kibert [3] defined the "High performance green building" as facilities designed, built, operated, renovated, and disposed of using ecological principles for the purpose of promoting occupant health and resource efficiency plus minimizing the impacts of the built environment on the natural environment.

According to OECD [4], generally, sustainability of the building or green building covered many issues from the design of the building, site selection, the specification of the materials and the efficiency of building system; to the construction which starts from the site preparation, the construction protection, and the minimization of the construction waste. The green building also has included the operation and resources used after the building was occupied which consisted over its operation life-time.

When comparing the globally well-known Green Building standard or rating system, it is important to 
consider the criteria within the Green Building rating system. For example, LEED V 4.0 [5] which is currently an active version, is comprised of 6 categories including; the sites and sustainability, the location and transportation, the water efficiency, the indoor environment quality, the material and researches, and the energy and atmosphere. These criteria for each program have its coverage in all aspects within the design, construction and operation of the building. Beside LEED's criteria, the other leading green building assessment tools including BRE Environmental Assessment Method (BREEAM, United Kingdom), Green Building Council of Australia Green Star (GBCA, Australia), or DGNB (Germany), might have a degree of dissimilarity. However, they were created on the similar basis of sustainability as shown in the image below.

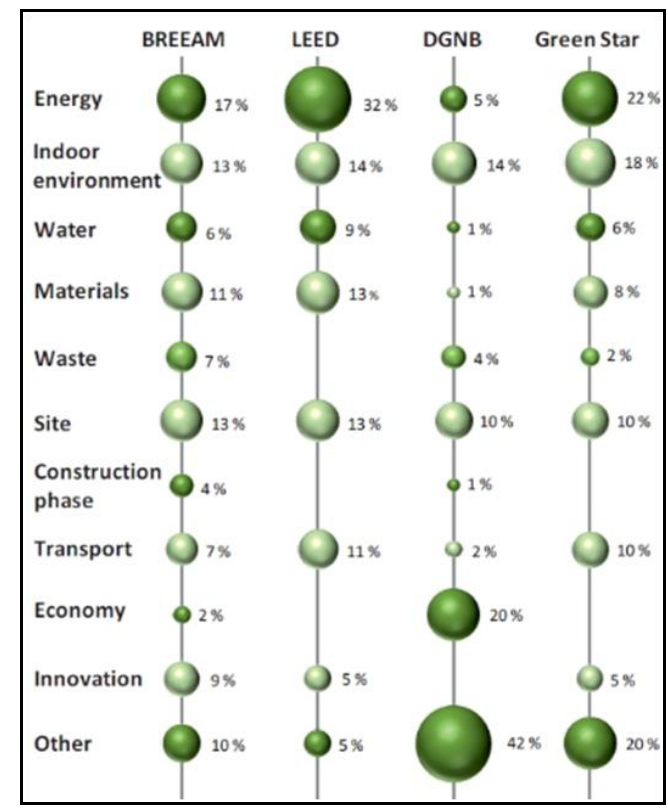

Figure 1. Comparison of green building standard [6].

Jian Zuoa and Zhen-Yu Zhao [7] reported that the focused aspect of the Green Building assessment tools was mainly placed on environmental aspects of sustainability shown in the criteria including energy efficiency, water efficiency, resource efficiency and greenhouse gas emission reduction.

However, the improvement of these assessment tools in the last decade showed the growing concerns of social sustainability in buildings. In the construction context, social sustainability mainly covers the better quality of living, occupational health and safety, and the future professional development opportunities, while in building context, social sustainability means providing a healthy and safe environment to all stakeholders including building occupants, residents, the construction personnel and other users and operators of the property which should be taken into account during the sustainable design process [7]. Moreover, the corporate social responsibility or CSR of the corporations was also the accelerating factor which the construction or real estate development companies often featured in their sustainability report [8].
Valdes-Vasquez and Klotz [9] suggested that social sustainability should be taken into consideration in construction projects right from the planning stage, including: engaging stake holders including end users, assessment of social impacts, and consideration of the local community.

Although the building design and construction of high performance buildings was dynamic and evolving, economic development aspects of sustainability in the green building were still left over. In LEED V4.0, the criteria which had an intention that involved the development of local community or the sharing to domestic economy were minimal. For example, the "Regional Material" in LEED V 4.0which provided the project an extra factor to calculate the credit in Material and Resources Categories in the case of specified and purchased building products sourced (extracted, manufactured, purchased) within 100 miles. This condition aimed to reduce the energy and carbonemissions during transportation rather than promoting the surrounding economy.

In order to fulfil the pillar of sustainability in all aspects, the green building standard and rating system should considered an option for the project to share an economic value along with the existing guidelines which aimed to both reduce as well as promote an environmental and social quality. One option is to elevate the regional material concept to meet the sustainability needs of the society, especially in Thailand where one particular concern is the sustainability of the rural community. There is an option for the green building to share its value to others.

\section{Natural handicrafts for architecture}

\subsection{Natural materials}

The definition of natural materials is simple; anything that is available in the nature could be identified as natural materials. However, in the domain of sustainability, 'natural materials' means an organic natural resource which could be renewable through naturally farming or plantation to overcome usage and consumption [10]. Rapidly renewable material is defined by the USGBC as a material that was able to regenerate itself in 10 years or less [5].

According to LEED V 4.0, the specification of natural material has been placed in the category of Material and Resources (MR) with the credit of Building product disclosure and optimization - sourcing of raw materials. The natural material was identified as (1) Bio-based materials which must meet the Sustainable Agriculture Network's Sustainable Agriculture Standard, their raw materials must be tested using ASTM Test Method D6866 and be legally harvested, as defined by the exporting and receiving country, and(2) Wood products which must be certified by the Forest Stewardship Council (FSC) or a USGBC-approved equivalent.

However, there were numerous types of natural materials that could be identified as green materials since they could be renewed rapidly and legally harvested. 
There were also the traditional buildings that were made of the natural materials which provided many benefits to sustainability of the construction. Stefan Dirlich [11] mentioned that the advantages included the utilisation of natural building materials, relatively low energy content of building material, excellent energy-efficiency during the phase of use and natural thermal insulation.

The study by Panyakaew and Fotios [12] showed the performance of insulation materials in the property. Bagasse, rice hulls and coconut coir were shown to offer the greatest potential for manufacturing into thermal insulation products.

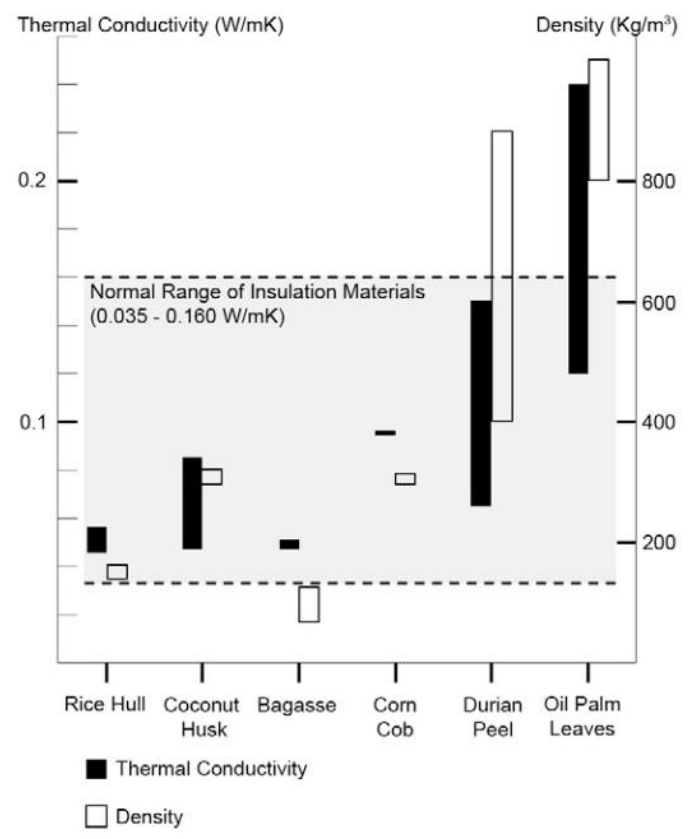

Figure 2. Comparison of thermal conductivities and densities of insulation board made from agricultural waste materials [12].

As mentioned earlier in this paper; most of the green building assessment tools had mainly focused on minimizing the environmental impact. Subsequently they missed an opportunity to promote sustainable business by promoting the usage of natural material.

\subsection{Domestic handicrafts}

As mentioned above, traditional buildings were made of natural materials such as; bamboo, rattan and vetiver, which can be found in the region, were produced with handcrafting. The natural building materials that were used in traditional construction were mostly sourced from the surrounding area or near the construction sites. The regional building materials also had relatively high shares of handwork positively affecting the local labour rmarket. These were generally user-friendly and easy-to-use materials and avoided damage to historic buildings by using existing technologies and materials. These materials adapted to most adverse conditions and enhanced the value of the building [11].

In Thailand and as in many Asian countries, handicrafts were not only the production or business, but have been the bond of the communities, creating jobs and generating substantial income in many rural areas of the country. Craftsmanship, for handicraft products, was a development in human society that transformed material into form and function by a community originating from the same location as the material. It contains knowledge and skills of the producers in the transforming of natural materials locally found such as bamboo, sage, rattan or even clay and metal into products [13].

However, after industrialisation, the handicraft was overcome by the mass production system. In order to compete with industrialised products, the craft producers had to sell their handmade products at a lower price [14]. The shift to mechanisation also changed people's lifestyle and their needs for products, therefore handicraft products gradually lost consumers. Unfortunately, handicraft producers were not aware of such avolatile threat and were unable to adapt themselves to meet the new demands from modern consumers.

\subsection{Case of thatch}

Thatch is a conventional vernacular construction material in many tropical regions. In Thailand, thatch was made by the wickerwork of Nipa Palm Leaves; the material that is made of natural leaves that grow along the mangroves and delta. It was once one of the major materials used in Thai traditional houses as a roofing material.

The decline of thatch demand consequentially led to the abandon of folk wisdom in the production of thatch as well as deforestation of the delta area since villagers did not perceive the Nipa Palm as their major source of income. Besides that, the income from the making of Nipa Palm thatch is relatively lower than other kinds of work especially when compared to the permanent workers in the factory sector or other service industries. This automatically triggered the collapse of the communities as a result of the abandonment of the villages by the younger generations.

However, thatch roofing has shown its ability tobe an excellent heat guard. From the experiment, the thatch was able to reduce $4.3 \mathrm{C}$ of the temperature in the under shade, compared to the normal galvanized steel roof. This is a substantial figure in terms of heat reduction, furthermore it consequentially reduced the energy used to cool the house by air-condition [15].

It was proven that the performance of the material (thatch) itself was able to help the design to achieve the required energy performance and the green certificates. But this data was unrecognized by the design and construction industry. Moreover, the industry would prefer to purchase an industrial product due to their convenience and ease in acquiring information about the products. As a result, there would be no business for natural handicraft building materials or products even if they possessed the necessary quality for green building.

In order to help the production of handicrafts and the community, there was a proposed promotional program that endorsed the design and construction industry to specify and purchase these products. One of the tools that could help promoting them was the green building mechanisms that have the criteria required for the 
building to specify and utilize handicraft products made from renewable natural material.

\section{Green sharing as a standard}

In order to share an economic value to the society while promoting the environmentally friendly and sustainable business, the authorities of the green building certificates and assessment tools should create criteria requiring that any project pursuing the certification must specify and purchase a certain amount of the natural handicraft building materials.

In Thailand, the components for this initiative already exist. On one side, TGBI or Thai Green Building Institute has created Thailand's green building assessment tool called "TREES Rating System" [16] which shares similarities with the LEED 2009 rating system. In this rating system, there is one criterion that demands the project to specify and purchase domestic products with an intention to promote the consumption of domestic building materials and reduce the energy used by transportation. This new credit that aimed to promote the natural handicraft building materials could be derived from the same method.

On the other hand, there are numerous handicraft producers that make the products for architectural projects. There was also a government initiative that intended to identify, develop and promote the handicraft producers by creating the standard for community products or Thai Community Product Standard (TCPS) which covered any type of products from food to furniture that could prove their authenticity as a community and therefore their consistency of production.

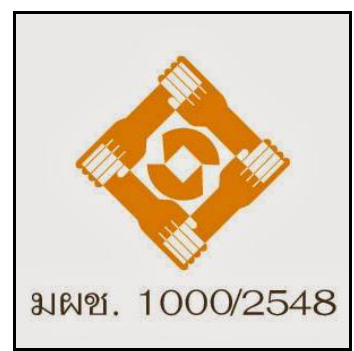

Figure 3. Mark of the standard of community product by Thailand Industrial Standard institute.

As of October 2015, there were 1,360 categories of standard that registered, but none of them have registered under building material or construction materials. These two components could create the mechanism that allows the community businesses to gain the economic value of the building and construction industry and thusly enable it to complete the basic pillar of sustainability.

In international cases, this initiative could be implemented through the green building rating system too. However, the verification mechanism to identify through natural community building products has to change. There were several international organizations, either governmental or non-profit private, that provided the verifying tools; for example, Fair Trade Organization, World Craft Organization. Green building organizations should work with assistance from those organizations in order to create the best mechanism for the green building to specify and purchase the products from the appropriate producers or suppliers.

\section{Conclusion}

The sustainability of the building and construction industry could be created not only from minimizing or eliminating the impact from the activities of the business, but also from sharing the economic value to the environment and society by specifying and selecting the handicraft products made from natural renewable material from the right producers.

To endorse the sharing, green building institutes should consider the idea of using the natural material handicraft as their credit in the material section of the green building standard. The credit award procedure should be studied in order to assure the integrity and transparency of the credit as well as the guidelines for the project developer, architect and green building practitioner to proceed to the credit.

On the other hand, the handicraft producers should be informed about the need for their product for the green building so that they can develop the products that are able to meet the requirements of the building and the criteria of the green building standard.

\section{References}

1. McGraw-Hill Construction, SmartMarket Report, (2013)

2. G. Brundtland, M. Khalid, S. Agnelli, S. Al-Athel, B. Chidzero, L. Fadika, V. Hauff, I. Lang, Ma Shijun, M.M. de Botero, M. Singh, S. Okita,Our Common Future ('Brundtland report $\backslash$ '), (1987)

3. C.J. Kilbert, Green Buildings: An Overview Of Progress, Journal of Land Use, 19, 2 (2004)

4. OECD, Design Of Sustainable Building Policies: Scope For Improvement And Barriers, (2002)

5. USGBC,LEED v4, LEED Reference Guide for Building Design and Construction, (2014)

6. P. Vladykova, Presentation in Chalmers Energy Conference 2013, (2013)

7. J. Zuoa, Z.Y. Zuoa, Green building research-current status and future agenda: A review, Renewable and Sustainable Energy Reviews, 30, 271-281, (2014)

8. K.D. Wong, Q. Fan, Building information modelling (BIM) for sustainable building design Facilities, 31, (3/4) (2013)

9. R. Valdes-Vasquez, L.E. Klotz, Social sustainability considerations during planning and design: A framework of processes for construction projects,J. Construct. Eng. Manage, 139, 1 (2013)

10. J.G. Stead, W.E. Stead, Management for a Small Planet, (2009)

11. S. Dirlich, The Building Stock and Traditional Building Principles: Sustainability Assessment for Historic Buildings,Proceedings of the 1st International Conference on Building Sustainability 
Assessment. Barcelos (Portugal): Green Lines Institute for Sustainable Development, (2012)

12. S. Panyakaew, S. Fotio, 321: Agricultural Waste Materials as Thermal Insulation forDwellings in Thailand: Preliminary Results, (2008)

13. V. Leesuwan, Thai Traditional Crafts, (1984)
14. V. Leesuwan, Wickerwork in Thailand, (1999)

15. Silpakorn University Research and Development Institute, Material and construction system in Thai vernacular house for sustainable living, (2005)

16. TGBI, TREES Rating System, (2009) 